\title{
An Integration of Neoclassical Growth Theory and Economic Structural Change with Monopolistic Competition Theory
}

\author{
Prof. Wei-Bin Zhang \\ Ritsumeikan Asia Pacific University, Japan \\ Tel: 0977-73-9787Ｅ-mail: wbz1@ @apu.ac.jp
}

Received: March 8, 2021 Accepted: April 2, 2021 Published: April 7, 2021

doi:10.5296/ber.v11i2.18380ＵRL: https://doi.org/10.5296/ber.v11i2.18380

\begin{abstract}
Wealth accumulation is a deterministic factor mechanism of national economic growth. Neoclassical growth theory is basically concerned with capital and wealth accumulation in perfectly competitive market. Global markets are characterized by a great variety of markets. Nevertheless, there only a few rigorous models of wealth accumulation with other types of markets within neoclassical growth framework. This study attempts to contribute literature of economic growth by introducing monopolistic competition and monopoly into neoclassical growth theory. The model is based on a few well-established economic theories. The model is constructed within framework of the Solow-Uzawa two-sector neoclassical growth model. The description of to monopolistic competition is influenced by the Dixit-Stiglitz model of monopolistic competition. The modelling of monopoly is based on monopoly theory. We model behavior of the household with Zhang's utility function and concepts of current income and disposable income. The unique contribution of this research is to integrate these theories in a comprehensive framework. We construct the basic model and then analyze properties of the model. The existence of a unique equilibrium point is identified by simulation. The effects of changes in some parameters comparative static analyses in some parameters.
\end{abstract}

Keywords: Monopoly, Dixit-Stiglitz model, Perfect competition, Profit, Solow-Uzawa model

\section{Introduction}

In modern economies different market structures co-exist. In one national economy, one observes perfect competition, imperfect competition, oligopoly, and monopoly. Different market structures have different economic efficiencies under varied economic mechanisms. Market structures have been extensively studied in different fields of microeconomics, mostly 
in partial and static frameworks (e.g., Nikaido, 1975; Mas-Colell, et al., 1995; Brakman and Heijdra, 2004; Wang, 2012; Behrens and Murata, 2007, 2017; and Parenti, et al., 2017). It is important to consider efficiencies and distributional impact of different markets in general equilibrium framework. Economists built a few formal growth models with microeconomic foundation which analyze behavior of different market structures in an integrated theory. This study contributes to the literature of neoclassical economic growth theory with capital and wealth accumulation by integrating different market structures within a single comprehensive framework. As far as I am aware, this is a first macroeconomic growth model of endogenous capital and wealth with monopoly, monopolistic competition, and perfect competition based on microeconomic foundation.

As far as capital and wealth accumulation is concerned, neoclassical growth theory is perhaps only a successful economic theory built on microeconomic foundation. Other economic theories such as new growth theory and economic development theories either omit physical capital or treat physical capital without proper microeconomic foundation. As history of contemporary economics shows, it is mathematically difficult to integrate some important ideas about imperfection competition in other economic theories into neoclassical grow theory. A main reason for that neoclassical economic theory can be further generalized is due to Zhang's model of household behavior. Zhang (2020) applies the approach to integrate various economic theories within a single comprehensive framework. The approach solves different economic problems with a single analytical framework. This study also applies the general economic theory to examine another important economic problem - how to analyze different market structures within an integrated framework with the growth mechanism of neoclassical growth theory. We apply two core models in economic theory to build our general model. The two models are respectively the Dixit-Stiglitz monopolistic competition equilibrium model (Dixit and Stiglitz, 1977) and the Solow-Uzawa two-sector growth model with perfect competition (Solow, 1956; Uzawa, 1961). The two models have resulted in two extensive but separate literatures of economic development. There is an extensive literature of neoclassical economics of perfect competition (e.g., Burmeister and Dobell, 1970; Azariadis, 1993; Barro and Sala-i-Martin, 1995; Jensen and Larsen, 2005; Zhang, 2005; and Ben-David and Loewy, 2003). The literature of monopolistic competition (which does not properly deal with wealth and physical capital accumulation) is extensive and is still developed fast (e.g., Krugman, 1979; Lancaster, 1980; Ethier, 1982; Romer, 1990; Benassy, 1996; Picard and Toulemonde, 2009; Bertoletti and Etro, 2015; Nocco, et al., 2017). Zhang (2018) recently integrates the two approaches. This study is to develop Zhang's model by introducing monopoly and economic structure into growth theory with wealth and capital accumulation. The rest of the paper is organized as follows. Section 2 builds the growth model of wealth and capital accumulation with monopoly, monopolistic competition, and perfect competition. Section 3 analyzes behavior of the model and illustrates properties of the model by simulation. Section 4 studies the effects of changes in some parameters on the economic system. Section 5 concludes the study.

\section{The Dynamic Model with Monopoly and Monopolistic Competition}

This study integrates monopoly with Zhang's monopolistic competition growth model (Zhang, 
2018). We build the model by integrating the Solow-Uzawa economic structural change and growth model, the Dixit-Stiglitz monopolistic competition model with product variety, monopoly theory in managerial economic, and Zhang's utility function and concepts of current and disposable incomes. The unique contribution of this study is to introduce monopoly and economic structure to Zhang's model. In the Dixit and Stiglitz model (Dixit and Stiglitz, 1977), economic production is divided into the production of a variety of differentiated middle products and the production of a final good. In addition to the Dixit-Stiglitz's product varieties, this study includes monopoly and monopoly product. Monopoly product is solely consumed by consumers. We apply the Solow model to describe the final goods production. The Solow good can be used as investment as capital good and consumed as consumer good. The production of final good uses labor and capital as input factors. Different from the Grossman-Helpman model (Grossman and Helpman, 1990) in wealth and capital are not included, we include the growth mechanism of the Solow model. Productions of intermediate inputs, final goods, and monopoly product all employ labor force. We select the final good as a medium of exchange. It is treated as numeraire. Capital is assumed to depreciate at a constant exponential rate $\delta_{k}$.

\section{The final good production}

We use $K_{i}(t), N_{i}(t)$, and $F_{i}(t)$, to stand for, respectively, capital input, labor input, and output of the final goods sector. Let $X_{i}(t)$ represent the intermediate inputs' (aggregate) input of the final good sector:

$$
X_{i}(t)=\sum_{\varepsilon=1}^{n} x_{\varepsilon}^{\theta}(t), 0<\theta<1
$$

Where $\theta$ is a parameter, $x_{\varepsilon}(t)$ is the input of middle product $\varepsilon, n$ stands for the number of varieties of middle products. Following Grossman and Helpman (1990), we apply the following production function of final goods:

$$
\begin{gathered}
F_{i}(t)=A_{i} K_{i}^{\alpha_{i}}(t) N_{i}^{\beta_{i}}(t) X_{i}^{\gamma_{i}}(t), \\
0<\alpha_{i}, \beta_{i}, \alpha_{i}+\beta_{i}<1, \gamma_{i}=\frac{1-\alpha_{i}-\beta_{i}}{\theta}>0
\end{gathered}
$$

where $A_{i}, \alpha_{i}$ and $\beta_{i}$ stand for parameters. The specified form implies that production is characterized by constant returns to scale for fixed $n$, but by increasing returns in $n$. This models the property that as degree of specialization is increased, technical efficiency in enhanced as $n$ is expanded. An additional type of new middle products enhances the degree of specialization. There are thus scale economies at the industry level which are exogenous to the final goods sector's individual firms. Let $w(t), r(t)$, and $p_{\varepsilon}(t)$, denote respectively the wage rate, the interest rate, and the price of middle good $\varepsilon$. We have the profit of the final goods sector:

$$
\pi_{i}(t)=F_{i}(t)-\left(r(t)+\delta_{k}\right) K_{i}(t)-w(t) N_{i}(t)-\sum_{\varepsilon=1}^{n} p_{\varepsilon}(t) x_{\varepsilon}(t)
$$




\section{Macrothink}

We have the following marginal conditions:

$$
r(t)+\delta_{k}=\frac{\alpha_{i} F_{i}(t)}{K_{i}(t)}, w(t)=\frac{\beta_{i} F_{i}(t)}{N_{i}(t)}, \quad p_{\varepsilon}(t)=\frac{\gamma_{i} \theta x_{\varepsilon}^{\theta-1}(t) F_{i}(t)}{X_{i}(t)}
$$

We see that the share of factor $X_{i}$ equals $\gamma_{i} F_{i}$. From the marginal conditions for capital and labor in (3) and (2), we get:

$$
K_{i}(t)=\Lambda(t) X_{i}^{\widetilde{\gamma}}(t), \quad N_{i}(t)=\left(\frac{w(t)}{\beta_{i} A_{i} K_{i}^{\alpha_{i}}(t) X_{i}^{\gamma_{i}}(t)}\right)^{1 /\left(\beta_{i}-1\right)}
$$

where $\tilde{\gamma} \equiv \gamma /\left(1-\alpha_{i}-\beta_{i}\right)$ and

$$
\Lambda(r, w, t) \equiv\left[\left(\frac{r_{\delta}(t)}{\alpha_{i} A_{i}}\right)^{\beta_{i}-1}\left(\frac{\beta_{i} A_{i}}{w(t)}\right)^{\beta_{i}}\right]^{1 /\left(1-\alpha_{i}-\beta_{i}\right)}, r_{\delta}(t) \equiv r(t)+\delta_{k}
$$

We see $\Lambda(t)$ independent of variety. With (3), we solve:

$$
p_{\varepsilon}(t)=\frac{\gamma_{i} \theta r_{\delta}(t) x_{\varepsilon}^{\theta-1}(t) \Lambda(t) X_{i}^{\widetilde{\gamma}-1}(t)}{\alpha_{i}}
$$

Substituting (4) into (5) yields:

$$
x_{\varepsilon}(t)=\tilde{\Lambda}(t) X_{i}^{(\widetilde{\gamma}-1) \bar{\theta}}(t) p_{\varepsilon}^{-\bar{\theta}}(t)
$$

where

$$
\tilde{\Lambda}(t) \equiv\left(\frac{\gamma_{i} \theta r_{\delta}(t) \Lambda(t)}{\alpha_{i}}\right)^{\bar{\theta}}, \bar{\theta} \equiv \frac{1}{1-\theta}
$$

We see that $\tilde{\Lambda}(t)$ is independent of variety. We calculate the share of variety $\varepsilon$ in terms of the total value of intermediate inputs as:

$$
\varphi_{\varepsilon}(t) \equiv \frac{x_{\varepsilon}(t) p_{\varepsilon}(t)}{\sum_{m=1}^{n} x_{m}(t) p_{m}(t)}
$$

From (6) and (7) we have

$$
\varphi_{\varepsilon}(t)=\frac{p_{\varepsilon}^{1-\bar{\theta}}(t)}{\sum_{m=1}^{n} p_{m}^{1-\bar{\theta}}(t)}
$$

\section{The middle goods sector}

It is assumed that decision on the production of middle goods is made in oligopolistic price competition market. The profit is the product of profits per unit of product and the share of the market. The producer of variety $\varepsilon$ chooses the price $p_{\varepsilon}(t)$ to maximizes the profit: 


$$
\pi_{\varepsilon}(t)=\left[p_{\varepsilon}(t)-a_{N} w(t)\right] \frac{\varphi_{\varepsilon}(t) \gamma_{i} F_{i}(t)}{p_{\varepsilon}(t)}
$$

in which $a_{N}$ stands for the unit labor requirement for production of intermediates. With this equation and (8), we get:

$$
\pi_{\varepsilon}(t)=\left[p_{\varepsilon}(t)-a_{N} w(t)\right] \frac{\gamma_{i} F_{i}(t) p_{\varepsilon}^{-\bar{\theta}}(t)}{\sum_{m=1}^{n} p_{m}^{1-\bar{\theta}}(t)}
$$

With (3) and (1), we get:

$$
F_{i}(t)=\frac{p_{\varepsilon}(t)}{\gamma_{i} \theta x_{\varepsilon}^{-1 / \bar{\theta}}(t)} \sum_{m=1}^{n} x_{m}^{\theta}(t)
$$

With (6) and (10), we obtain:

$$
\frac{F_{i}(t)}{\sum_{m=1}^{n} p_{m}^{1-\bar{\theta}}(t)}=\frac{\widetilde{\Lambda}(t) X_{i}^{(\widetilde{\gamma}-1) \bar{\theta}}(t)}{\gamma_{i} \theta}
$$

From (9) and (11), we get the following profit function:

$$
\pi_{\varepsilon}(t)=\left[p_{\varepsilon}(t)-a_{N} w(t)\right] \frac{\gamma_{i} \tilde{\Lambda}(t) X_{i}^{(\widetilde{\gamma}-1) \bar{\theta}}(t) p_{\varepsilon}^{-\bar{\theta}}(t)}{\gamma_{i} \theta}
$$

From the first-order condition (i.e., $\partial \pi_{\varepsilon} / \partial p_{\varepsilon}=0$ ) of maximizing the profit, we have the fixed-markup pricing rule as follows:

$$
\theta p_{\varepsilon}(t)=a_{N} w(t)
$$

We see the price independent of variety. By (9) and (12), the profit per firm is given by:

$$
\pi(t)=\frac{(1-\theta) \gamma_{i} F_{i}(t)}{n}
$$

By (13), we see the profit independent of $\varepsilon$. With (5), we also see $x_{\varepsilon}(t)$ independent of $\varepsilon$. We denote $x_{\varepsilon}(t)$ by $x(t)$. With (1) we obtain:

$$
X_{i}(t)=n x^{\theta_{i}}(t)
$$

We have the total profit as:

$$
\bar{\pi}(t)=n \pi(t)
$$

\section{Modelling the consumer behavior with saving}

We apply Zhang's model of household behavior (Zhang, 1993, 2020). Let $\bar{k}(t)$ denote per capita wealth. We thus have: $\bar{k}(t)=K(t) / N$, where $K(t)$ stands for the total capital. All the profits are equally shared among the population. In many of formal growth models it is commonly assumed that profit is often invested for innovation. The total profit is assumed to be equally distributed between the homogenous households in this study. It is more realistic 
to take account of various possible distributions of profits among firms, households, and governments. We use $h$ to stand for human capital. We have the representative household's current income as:

$$
y(t)=r(t) \bar{k}(t)+h w(t)+\frac{\bar{\pi}(t)}{\bar{N}}+\frac{\pi_{m}(t)}{\bar{N}}
$$

We have the household disposable income $\hat{y}(t)$ as the value of wealth and the current disposable income:

$$
\hat{y}(t)=y(t)+\bar{k}(t)
$$

The disposable income is assumed to be what is available for the representative household to use for consumption of monopoly product $c_{m}(t)$, and consumption of final goods $c_{i}(t)$, and savings $s(t)$. We express the budget constraint:

$$
p_{m}(t) c_{m}(t)+c_{i}(t)+s(t)=\hat{y}(t)
$$

where $p_{m}(t)$ is the price of monopoly product. The utility level $U(t)$ is taken on the following form which is dependent on $c_{m}(t), c_{i}(t)$, and $s(t)$ :

$$
U(t)=\left(\xi_{m} c_{m}^{\xi_{0}}(t)+\xi_{i} c_{i}^{\xi_{0}}(t)\right)^{1 / \xi_{0}} s^{\lambda_{0}}(t), \quad \xi_{m}, \xi_{i}, \xi_{0}, \lambda_{0}>0
$$

where $\lambda_{0}$ stands for the propensity to save. Appendix A1 solves the optimal problem with the following expressions:

$$
\begin{gathered}
c_{m}(t)=\xi P(t) \hat{y}(t) \Lambda(t), \quad c_{i}(t)=\xi \hat{y}(t) \Lambda(t) \\
s(t)=\left(P^{\xi_{0}}(t)+\xi\right) \lambda_{0} \hat{y}(t) \Lambda(t)
\end{gathered}
$$

where

$$
\begin{gathered}
\Lambda(t) \equiv \frac{1}{\xi p_{m}(t) P(t)+\lambda_{0} P^{\xi_{0}}(t)+\lambda}, P(t) \equiv \xi^{\frac{1}{\left(\xi_{0}-1\right)}} p_{m}^{\frac{1}{\left(\xi_{0}-1\right)}}(t), \\
\lambda \equiv \xi+\lambda_{0} \xi, \xi \equiv \frac{\xi_{i}}{\xi_{m}} .
\end{gathered}
$$

The behavior of the household is known if we get $p_{m}(t)$ and $\hat{y}(t)$.

\section{Wealth accumulation}

According to the definition of $s(t)$, we have the following equation for describing the change in the household's wealth is given by:

$$
\dot{\bar{k}}(t)=s(t)-\bar{k}(t)=\left(P^{\xi_{0}}(t)+\xi\right) \lambda_{0} \hat{y}(t) \Lambda(t)-\bar{k}(t)
$$

This equation simply says that saving minus dissaving is the change in wealth.

\section{Equilibrium for monopoly product}




\section{N Macrothink}

Business and Economic Research

ISSN 2162-4860

2021, Vol. 11, No. 2

Let $F_{m}(t)$ represent the monopoly's output. We have the demand and supply condition for monopoly product as:

$$
c_{m}(t) \bar{N}=F_{m}(t)
$$

\section{The behavior of the monopoly}

As the monopoly has monopolistic power, the price is determined by itself. Let $K_{m}(t)$ and $N_{m}(t)$ stand for respectively the capital input and labor input of the monopoly. The production function of the monopoly is sepcified:

$$
F_{m}(t)=A_{m} K_{m}^{\alpha_{m}}(t) N_{m}^{\beta_{m}}(t), \quad 0<\alpha_{m}, \beta_{m}<1
$$

in which $A_{m}, \alpha_{m}$ and $\beta_{m}$ are parameters. The monopoly's profit equals:

$$
\pi_{m}(t)=p_{m}(t) F_{m}(t)-\left(r(t)+\delta_{k}\right) K_{m}(t)-w(t) N_{m}(t)
$$

With (20) and (22) we get:

$$
p_{m}(t) F_{m}(t)=p_{m}(t) c_{m}(t) \bar{N}=\frac{\bar{\xi} \hat{y}(t)}{\bar{\lambda}+P^{-\xi_{0}(t)}}
$$

where

$$
\bar{\xi} \equiv \frac{\bar{N}}{\lambda}, \quad \bar{\lambda} \equiv \frac{\left(1+\lambda_{0}\right)}{\lambda}
$$

With (17) and (24), we obtain:

$$
\hat{y}(t)=\tilde{y}(t)+\frac{p_{m}(t) F_{m}(t)}{\bar{N}}
$$

where

$$
\tilde{y}(t)=(1+r(t)) \bar{k}(t)+h w(t)+\frac{\bar{\pi}(t)}{\bar{N}}-\frac{\left(r(t)+\delta_{k}\right) K_{m}(t)+w(t) N_{m}(t)}{\bar{N}}
$$

The above equation and (25) imply:

$$
\left(\bar{\lambda}-\frac{\bar{\xi}}{\bar{N}}\right) p_{m}(t)+\xi^{\frac{\xi_{0}}{\left(1-\xi_{0}\right)}} p_{m}^{\frac{1}{\left(1-\xi_{0}\right)}}(t)=\frac{\bar{\xi} \tilde{y}(t)}{F_{m}(t)}
$$

We solve the equation with the variable $p_{m}(t)$ as a function of $F_{m}(t)$ and $\tilde{y}(t)$. For instance, we can explicitly solve the equation when $\xi_{0}=1 / 2$ or 2 . Suppose there is a solution expressed as follows: $p_{m}(t)=G\left(F_{m}(t)\right)$. The profit is now given by:

$$
\pi_{m}(t)=G\left(F_{m}(t), \tilde{y}(t)\right) F_{m}(t)-\left(r(t)+\delta_{k}\right) K_{m}(t)-w(t) N_{m}(t)
$$

We maximize the profit in capital and labor and have the following marginal conditions: 


$$
\begin{gathered}
\frac{\partial \pi_{m}}{\partial K_{m}}=\left(F_{m} \frac{\partial G}{\partial F_{m}}+G\right) \frac{\alpha_{m} F_{m}}{K_{m}}-\left(\frac{1}{\bar{N}} \frac{\partial G}{\partial \tilde{y}}+1\right)\left(r+\delta_{k}\right)=0 \\
\frac{\partial \pi_{m}}{\partial N_{m}}=\left(F_{m} \frac{\partial G}{\partial F_{m}}+G\right) \frac{\beta_{m} F_{m}}{N_{m}}-\left(\frac{1}{\bar{N}} \frac{\partial G}{\partial \tilde{y}}+1\right) w=0
\end{gathered}
$$

where we don't include time in the expressions. These two equations enable us to decide the labor and capital inputs as functions of the rest variables in the system. With (23) and (26) we determine the price and output of monopoly product. We have the monopoly's profit with (27). One finds to analyze behavior of monopoly in more general form in some standard microeconomic textbooks (e.g., Mas-Colell, et al., 1995).

\section{Demand and supply of final goods}

As change in capital stock equal to the output of the final goods sector is minus the depreciation of capital stock and total consumption, we have:

$$
\dot{K}(t)=F_{i}(t)-C_{i}(t)-\delta_{k} K(t)
$$

where $C_{i}(t)=c_{i}(t) \bar{N}$.

\section{Full employment of labor and capital}

In labor market, the labor supply equals the labor demand:

$$
N_{i}(t)+N_{m}(t)+a_{N} x(t) n=h \bar{N}
$$

For capital markets we have:

$$
K_{i}(t)+K_{m}(t)=\bar{k}(t) \bar{N}
$$

We constructed the model. It is an integration of the Solow model, the Dixit-Stiglitz model, the Grossman-Helpman model, and theory of monopoly with Zhang's utility function and concepts of current and disposable income. The rest of the paper analyzes properties of the economic system.

\section{Properties of the Monopoly-monopolistic-competitive Model}

The previous section constructed the growth model with monopoly, monopolistic competition, and perfect competition. To simulate the model, we need a computational program to follow the movement of the economic system.

\section{Lemma}

The movement of the model is determined by a differential equation as follows:

$$
\dot{x}(t)=\left(\frac{d \bar{\varphi}(x(t))}{d x(t)}\right)^{-1} f(x(t))
$$

where functions $\bar{\varphi}(x(t))$ and $f(x(t))$ are defined in Appendix A-2. All the other variables are explicitly given as functions of $x(t)$ as follows: $\bar{k}(t)$ with (A14) $\rightarrow z(t)$ by (A11) $\rightarrow$ $K(t)=\bar{k}(t) \bar{N} \rightarrow F_{i}(t)$ by $(\mathrm{A} 6) \rightarrow w(t)$ by $(\mathrm{A} 7) \rightarrow r(t)$ by $(\mathrm{A} 12) \rightarrow \pi(t)$ by $(13) \rightarrow$ 


\section{MInstitute Macrothink}

$\bar{\pi}(t)$ by $(15) \rightarrow X_{i}(t)$ by $(14) \rightarrow p_{\varepsilon}(t)$ by (A2) $\rightarrow N_{i}(t)$ by (A4) $\rightarrow N_{m}(t)$ by (A8) $\rightarrow$ $K_{i}(t)$ and $K_{m}(t)$ by (A9) $\rightarrow F_{m}(t)$ by (A10) $\rightarrow \varphi(t)$ by $(8) \rightarrow p_{m(t)}$ by $(26) \rightarrow \pi_{m}(t)$ by $(27) \rightarrow \hat{y}(t)$ by $(17) \rightarrow c_{i}(t), c_{m}(t)$ and $s(t)$ by (20).

For illustration, the model is simulated. We first solve (26). For solving the problem, we specify $\xi_{0}=1 / 2$. The specified value is assumed in the rest of the paper. With this specification, we have (26) in the following form:

$$
\left(\frac{\bar{\lambda}}{\bar{\xi}}-\frac{\bar{\xi}}{\xi \bar{N}}\right) p_{m}(t)+p_{m}^{2}(t)=\frac{\bar{\xi} \tilde{y}(t)}{\xi F_{m}(t)}
$$

We solved the above equation and obtain the following unique relation between $p_{m}$ and $F_{m}$ and $\tilde{y}$ :

$$
p_{m}=\left(\bar{\lambda}_{1}^{2}+\left(\frac{\bar{\xi} \tilde{y}}{\xi F_{m}}\right)\right)^{1 / 2}-\bar{\lambda}_{1}
$$

where

$$
\bar{\lambda}_{1} \equiv\left(\bar{\lambda}-\frac{\bar{\xi}}{\bar{N}}\right) \frac{1}{2 \bar{\xi}}
$$

Equation (30) and the Lemma imply:

$$
\Psi_{x}(x, \bar{k}) \equiv\left(F_{m} \frac{\partial p_{m}}{\partial F_{m}}+G\right) \frac{\beta_{m} F_{m}}{N_{m}}-\left(\frac{1}{\bar{N}} \frac{\partial p_{m}}{\partial \tilde{y}}+1\right) w=0
$$

The equilibrium condition for (20) means:

$$
\Psi_{k}(x, \bar{k}) \equiv\left(P^{\xi_{0}}+\xi\right) \lambda_{0} \hat{y} \Lambda-\bar{k}=0
$$

With (33) and (34) we get $x$ and $\bar{k}$. To determine all the equilibrium values of the variables we specify, we take on the following values of the rest parameters:

$$
\begin{gathered}
\boldsymbol{N}_{\mathbf{0}}=\mathbf{1 0}, \boldsymbol{h}=\mathbf{3}, \boldsymbol{A}_{\boldsymbol{i}}=\mathbf{1 . 1}, \boldsymbol{\alpha}_{\boldsymbol{i}}=\mathbf{0 . 3}, \boldsymbol{\beta}_{\boldsymbol{i}}=\mathbf{0 . 4} ; \boldsymbol{\theta}=\mathbf{0 . 3}, \boldsymbol{A}_{\boldsymbol{m}}=\mathbf{1 . 1}, \\
\alpha_{m}=0.3, \beta_{m}=0.7, n=10, a_{N}=0.4, \lambda_{0}=0.7, \xi_{i}=0.5, \xi_{m}=0.5, \\
\delta_{k}=0.05
\end{gathered}
$$

We specify the population at 10 and the human capital at 3 . The number of varieties of intermediate inputs is 10 . We do not refer the specified values of the parameters to a real economy. We try to obtain some insights into economic mechanism of growth by analyzing effects of different values of these parameters on the economic system. The existence of an equilibrium point of (33) and (34) is illustrated in Figure 1. 


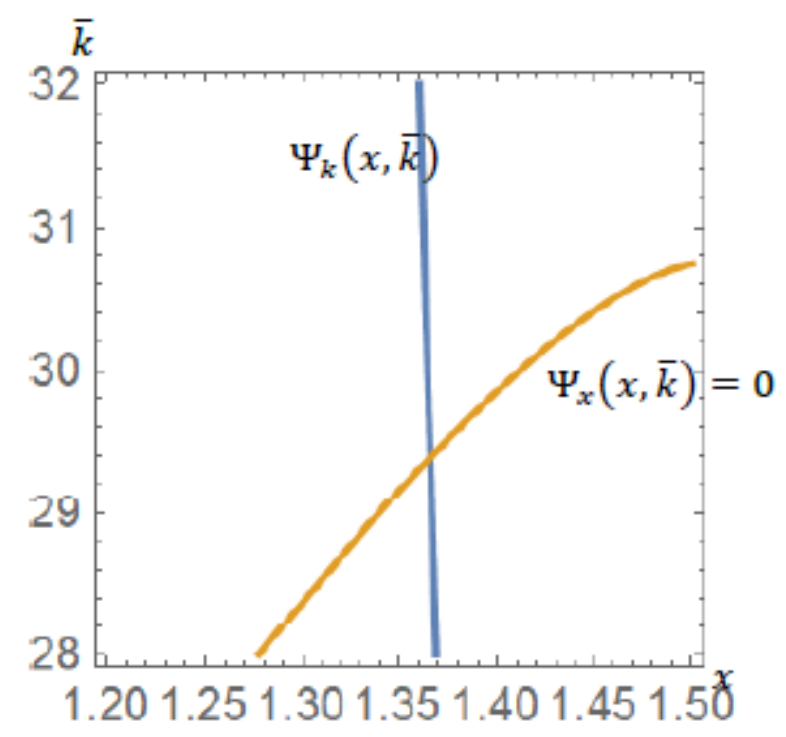

Figure 1. The Contours of the Two Curves

The simulation identifies the values of the two variables as follows:

$$
x=1.366, \bar{k}=29.39
$$

The corresponding equilibrium values are listed as follows:

$$
\begin{gathered}
K=293.9 .59, \quad Y=405.2, F_{m}=7.11, N_{m}=3.73, K_{m}=32.14, F_{i}=243.9, \\
K_{i}=261.8, X_{i}=10.98, \quad N_{i}=20.81, N_{x}=5.46, \quad x=1.37, \pi_{0}=19.92, \\
\pi_{m}=26.25, \quad r=0.183, \quad w=4.69, \quad p_{\epsilon}=6.25, \quad p_{m}=7.2, \hat{y}=71.38, \\
\bar{k}=29.39, \quad c_{i}=36.87, c_{m}=0.71, \quad U=127.4
\end{gathered}
$$

In (36), the national income is defined as:

$$
Y=r K+h w \bar{N}+\pi_{m}+\bar{\pi} .
$$

Solow's goods sector has zero profit under the assumption of perfect competition. The firms of monopolistic competition and monopoly earn positive profits. We now study how the equilibrium structure is shifted as we vary the parameter values.

\section{Comparative Static Analysis}

In the previous section we determined the economic structure. This section shows how changes in some parameter values affect the national economy. As the Lemma provides a computational procedure to calibrate the model, we can easily give the effects of shifts in any parameter value on the long-term economic structure. We introduce a variable $\bar{\Delta} x$ to stand for the change rate of the variable $x$ in percentage due to a given change in the parameter value.

\subsection{The Total Factor Productivity of the Monopoly is Increased}

We first examine what happen to the economic structure if the monopoly enhances its total 


\section{$\Lambda$ Macrothink}

factor productivity as follows: $A_{m}=1$ to 1.1 . We list the effects on the system in (37):

$$
\begin{gathered}
\bar{\Delta} K=\bar{\Delta} Y=0.02, \bar{\Delta} F_{m}=18.9, \bar{\Delta} N_{m}=8.07, \bar{\Delta} K_{m}=8.24, \bar{\Delta} F_{i}=-1.11, \\
\bar{\Delta} K_{i}=-1, \bar{\Delta} X_{i}=-0.34, \bar{\Delta} N_{i}=\bar{\Delta} N_{x}=-1.14, \bar{\Delta} x=-1.14, \bar{\Delta} \pi_{0}=-1.1, \\
\bar{\Delta} \pi_{m}=8.7, \bar{\Delta} r=-0.15, \bar{\Delta} w=0.04, \bar{\Delta} p_{\epsilon}=0.04, \bar{\Delta} p_{m}=-8.8, \bar{\Delta} \hat{y}=0.02, \\
\bar{\Delta} \bar{k}=0.02, \bar{\Delta} c_{i}=-1.15, \bar{\Delta} c_{m}=18.9, \bar{\Delta} U=1.21
\end{gathered}
$$

The monopoly produces more output and employs more labor force and capital stock. Its profit is increased in association with fall in its price. The national capital and national income are augmented. The final goods sector produces less and employs less capital, intermediate goods and labor force. The representative firm in the intermediate sector employs less labor force and produces less. Its profit falls in association of a slight rise in its price. The wage rate is enhanced. The interest rate is reduced. The household's disposable income and wealth are increased. The household consumes fewer final goods but more monopoly product. The utility level is enhanced.

\subsection{The Total Factor Productivity of the Final Goods Sector is Increased}

We now examine what happen to the economic structure if the final goods sector's total factor productivity rises as follows: $A_{i}=1.1$ to 1.15 . We have the following effects as in (38):

$$
\begin{gathered}
\bar{\Delta} K=\bar{\Delta} Y=6.1, \bar{\Delta} F_{m}=-1.65, \bar{\Delta} N_{m}=-3.36, \bar{\Delta} K_{m}=2.48, \bar{\Delta} F_{i}=6.6, \\
\bar{\Delta} K_{i}=6.54, \bar{\Delta} X_{i}=0.14, \bar{\Delta} N_{i}=0.47, \bar{\Delta} N_{x}=0.47, \bar{\Delta} x=0.47, \bar{\Delta} \pi_{0}=6.6, \\
\bar{\Delta} \pi_{m}=2.28, \bar{\Delta} r=0.06, \bar{\Delta} w=6.09, \bar{\Delta} p_{\epsilon}=6.09, \bar{\Delta} p_{m}=4.12, \bar{\Delta} \hat{y}=6.1, \\
\bar{\Delta} \bar{k}=6.1, \quad \bar{\Delta} c_{i}=6.6, \bar{\Delta} c_{m}=-1.65, \bar{\Delta} U=10.06 .
\end{gathered}
$$

The monopoly produces less output and employs less labor force but more capital stock. Its profit is increased in association with rise in its price. The national capital and national income are augmented. The final goods sector produces more and employs more capital, intermediates and labor force. The representative firm in the intermediate sector employs more labor force and produces more. Its profit is increased in association of rise in its price. The wage rate is enhanced. The interest rate is increased. The household's disposable income and wealth are increased. The household consumes more final goods but less monopoly product. The utility level is enhanced.

\subsection{A rise in Output Elasticity of Intermediate Inputs in the Final Goods Production}

We now examine the impact of the following rise in output elasticity of intermediate inputs: $\theta=0.3 \Rightarrow 0.305$. The effects on the variables are listed in (39):

$$
\begin{gathered}
\bar{\Delta} K=\bar{\Delta} Y=-6.48, \bar{\Delta} F_{m}=-0.3, \bar{\Delta} N_{m}=1.6, \bar{\Delta} K_{m}=-4.65, \bar{\Delta} F_{i}=5.8 \\
\bar{\Delta} K_{i}=-6.7, \bar{\Delta} X_{i}=0.49, \bar{\Delta} N_{i}=-0.57, \bar{\Delta} N_{x}=\bar{\Delta} x=1.08, \bar{\Delta} \pi_{0}=-8.02, \\
\bar{\Delta} \pi_{m}=-3.55, \bar{\Delta} r=1.21, \bar{\Delta} w=-5.3, \bar{\Delta} p_{\epsilon}=-6.8, \bar{\Delta} p_{m}=-3.4 \\
\bar{\Delta} \hat{y}=-6.5, \bar{\Delta} \bar{k}=-6.5, \quad \bar{\Delta} c_{i}=-6.9, \bar{\Delta} c_{m}=-0.31, \bar{\Delta} U=-10.4
\end{gathered}
$$

The intermediate sector produces more and employs more labor force. The price of intermediates is reduced and the profit of the representative firm in the sector falls. The national income and national output fall. The monopoly produces less output and employs 
more labor force but less capital stock. Its profit is reduced in association with fall in its price. The final goods sector produces more output and employs less capital, and labor force but more intermediates. The wage rate is reduced. The interest rate is increased. The household's disposable income and wealth are reduced. The household consumes fewer final goods and monopoly product. The utility level is reduced.

\subsection{A rise in Cost of Intermediate Production}

We now examine the impact of the following rise in cost of intermediate production: $a_{N}=0.4 \Rightarrow 0.42$. We get the effects as in (40):

$$
\begin{gathered}
\bar{\Delta} K=\bar{\Delta} Y=-2.25, \bar{\Delta} F_{m}=0.63, \bar{\Delta} N_{m}=1.32, \bar{\Delta} K_{m}=-0.94, \bar{\Delta} F_{i}=-2.43 \\
\bar{\Delta} K_{i}=-2.41, \bar{\Delta} X_{i}=-1.51, \bar{\Delta} N_{i}=\bar{\Delta} N_{x}=-0.19, \bar{\Delta} x=-5, \bar{\Delta} \pi_{0}=-2.4, \\
\bar{\Delta} \pi_{m}=-0.9, \bar{\Delta} r=-0.02, \bar{\Delta} w=-2.3, \bar{\Delta} p_{\epsilon}=2.64, \bar{\Delta} p_{m}=-1.5 \\
\bar{\Delta} \hat{y}=-2.3, \bar{\Delta} \bar{k}=-2.3, \bar{\Delta} c_{i}=-2.4, \bar{\Delta} c_{m}=0.6, \bar{\Delta} U=-3.6 .
\end{gathered}
$$

The intermediate sector produces less and employs less labor force. The price of intermediates is increased but the profit of the representative firm in the sector falls. The national income and national output fall. The monopoly produces more output and employs more labor force but less capital stock. Its profit is reduced in association with fall in its price. The final goods sector produces less output and employs less capital, intermediates and labor force. The wage rate is reduced. The interest rate is decreased. The household's disposable income and wealth are reduced. The household consumes less final goods but more monopoly product. The utility level is reduced.

\subsection{A Rise in the Share of Monopoly Product in the Utility Function}

We now examine the impact of the following rise in share of monopoly product in the utility function: $\xi_{m}=0.5 \Rightarrow 0.51$. We get the effects as in (41):

$$
\begin{gathered}
\bar{\Delta} K=\bar{\Delta} Y=0.004, \bar{\Delta} F_{m}=3.33, \bar{\Delta} N_{m}=3.31, \bar{\Delta} K_{m}=3.37, \bar{\Delta} F_{i}=-0.46, \\
\bar{\Delta} K_{i}=-0.4, \bar{\Delta} X_{i}=-0.14, \bar{\Delta} N_{i}=\bar{\Delta} N_{x}=-0.5, \bar{\Delta} x=-0.5, \bar{\Delta} \pi_{0}=-0.46, \\
\bar{\Delta} \pi_{m}=3.51, \bar{\Delta} r=-0.06, \bar{\Delta} w=0.02, \bar{\Delta} p_{\epsilon}=0.02, \bar{\Delta} p_{m}=0.1, \bar{\Delta} \hat{y}=0.004, \\
\bar{\Delta} \bar{k}=0.004, \bar{\Delta} c_{i}=-0.47, \bar{\Delta} c_{m}=3.33, \bar{\Delta} U=0.49 .
\end{gathered}
$$

The monopoly produces more output and employs more labor force and capital stock. Its profit is increased in association with rise in its price. The national capital and national income are slightly augmented. The final goods sector produces less and employs less capital, intermediates and labor force. The representative firm in the intermediate sector employs less labor force and produces less. Its profit falls in association of rise in its price. The wage rate is enhanced. The interest rate is reduced. The household's disposable income and wealth are slightly increased. The household consumes fewer final goods but more monopoly product. The utility level is enhanced.

\subsection{A Rise in the Share of Final Goods in the Utility Function}

We now examine the impact of the following rise in share of monopoly product in the utility function: $\xi_{i}=0.5 \Rightarrow 0.51$. We get the effects as in (42): 


\section{Mll Macrothink}

$$
\begin{gathered}
\bar{\Delta} K=\bar{\Delta} Y=-0.003, \bar{\Delta} F_{m}=-3.2, \bar{\Delta} N_{m}=-3.2, \bar{\Delta} K_{m}=-3.3, \bar{\Delta} F_{i}=0.44, \\
\bar{\Delta} K_{i}=0.4, \bar{\Delta} X_{i}=0.14, \bar{\Delta} N_{i}=0.5, \bar{\Delta} N_{x}=0.5, \bar{\Delta} x=0.5, \bar{\Delta} \pi_{0}=0.44, \\
\bar{\Delta} \pi_{m}=-3.4, \bar{\Delta} r=0.05, \bar{\Delta} w=-0.01, \bar{\Delta} p_{\epsilon}=-0.01, \bar{\Delta} p_{m}=-0.1, \\
\bar{\Delta} \hat{y}=-0.002, \bar{\Delta} \bar{k}=-0.003, \quad \bar{\Delta} c_{i}=0.46, \bar{\Delta} c_{m}=-3.2, \bar{\Delta} U=3.55 .
\end{gathered}
$$

The final goods sector produces more, employs more capital stock, labor force and intermediates. The monopoly produces less output and employs less labor force and capital stock. Its profit is reduced in association with fall in its price. The national capital and national income are reduced. The representative firm in the intermediate sector employs more labor force and produces more. Its profit rises in association of fall in its price. The wage rate is reduced. The household's disposable income and wealth are slightly decreased. The household consumes more final goods but less monopoly product. The utility level is increased in association.

\subsection{A Rise in the Propensity to Save}

We now examine the impact of the following rise in share of monopoly product in the utility function: $\lambda_{0}=0.7 \Rightarrow 0.71$. We get the effects as in (43):

$$
\begin{gathered}
\bar{\Delta} K=1.84, \bar{\Delta} Y=0.36, \bar{\Delta} F_{m}=0.54, \bar{\Delta} N_{m}=-0.02, \bar{\Delta} K_{m}=1.83, \bar{\Delta} F_{i}=0.46, \\
\bar{\Delta} K_{i}=1.85, \bar{\Delta} X_{i}=0.001, \bar{\Delta} N_{i}=\bar{\Delta} N_{x}=\bar{\Delta} x=0.002, \bar{\Delta} \pi_{0}=0.46, \\
\bar{\Delta} \pi_{m}=0.5, \bar{\Delta} r=-1.74, \bar{\Delta} w=0.46, \bar{\Delta} p_{\epsilon}=0.46, \bar{\Delta} p_{m}=-0.07, \bar{\Delta} \hat{y}=1, \\
\bar{\Delta} \bar{k}=1.85, \bar{\Delta} c_{i}=0.41, \bar{\Delta} c_{m}=0.54, \bar{\Delta} U=5.23
\end{gathered}
$$

The final goods sector produces more, employs more capital stock, labor force and intermediates. The monopoly produces more output, employs less labor force but more capital stock. Its profit is increased in association with fall in its price. The national capital and national income are augmented. The representative firm in the intermediate sector employs more labor force and produces more. Its profit is increased in association of rise in its price. The wage rate is enhanced. The household's disposable income and wealth are augmented. The household consumes more final goods and monopoly product. The utility level is increased.

\subsection{A Rise in the Population}

We now examine the impact of the following rise in share of monopoly product in the utility function: $\mathrm{N}_{0}=10 \Rightarrow 11$. We get the effects as in (44):

$$
\begin{gathered}
\bar{\Delta} K=\bar{\Delta} Y=10.01, \bar{\Delta} F_{m}=9.92, \bar{\Delta} N_{m}=9.92, \bar{\Delta} K_{m}=9.92, \bar{\Delta} F_{i}=10.01, \\
\bar{\Delta} K_{i}=10.01, \bar{\Delta} X_{i}=2.9, \bar{\Delta} N_{i}=\bar{\Delta} N_{x}=10.01, \bar{\Delta} x=10.02, \bar{\Delta} \pi_{0}=10.01, \\
\bar{\Delta} \pi_{m}=5.2, \bar{\Delta} r=-0.01, \bar{\Delta} w=\bar{\Delta} p_{\epsilon}=0.001, \bar{\Delta} p_{m}=0.04, \bar{\Delta} \hat{y}=0.01 \\
\bar{\Delta} \bar{k}=0.01, \bar{\Delta} c_{i}=0.01, \bar{\Delta} c_{m}=-0.08, \bar{\Delta} U=0.007
\end{gathered}
$$

The national economic variables are increased almost in the same proportion with the change rate in the population. The microeconomic variables are slightly affected. The effects on the system are different from the standard Solow-Uzawa neoclassical growth model in which the interest rate, wage rate and microeconomic variables in terms of per household are not affected in long-term equilibrium. 


\subsection{The Monopoly's Output Elasticity of Capital is Increased}

We now examine the impact of the following rise in share of monopoly product in the utility function: $\alpha_{m}=0.3 \Rightarrow 0.31$. We get the effects as in (45):

$$
\begin{gathered}
\bar{\Delta} K=\bar{\Delta} Y=-0.11, \bar{\Delta} F_{m}=8.4, \bar{\Delta} N_{m}=3.7, \bar{\Delta} K_{m}=6.7, \bar{\Delta} F_{i}=-0.64, \\
\bar{\Delta} K_{i}=-0.96, \bar{\Delta} X_{i}=-0.16, \bar{\Delta} N_{i}=-0.53, \bar{\Delta} N_{x}=-0.53, \bar{\Delta} x=-0.53, \\
\bar{\Delta} \pi_{0}=-0.64, \bar{\Delta} \pi_{m}=2.9, \bar{\Delta} r=0.4, \bar{\Delta} w=-0.1, \bar{\Delta} p_{\epsilon}=-0.1, \bar{\Delta} p_{m}=-4.3, \\
\bar{\Delta} \hat{y}=-0.12, \bar{\Delta} \bar{k}=-0.12, \bar{\Delta} c_{i}=-0.66, \bar{\Delta} c_{m}=8.4, \bar{\Delta} U=0.34,
\end{gathered}
$$

The monopoly produces more output and employs more labor force and capital stock. Its profit is increased in association with fall in its price. The national capital and national income are reduced. The final goods sector produces less and employs less capital, intermediates and labor force. The representative firm in the intermediate sector employs less labor force and produces less. Its profit falls in association of fall in its price. The wage rate is decreased. The interest rate is increased. The household's disposable income and wealth are reduced. The household consumes fewer final goods but more monopoly product. The utility level is enhanced.

\subsection{The Monopoly's Output Elasticity of Labor is Increased}

We now examine the impact of the following rise in share of monopoly product in the utility function: $\beta_{m}=0.3 \Rightarrow 0.31$. The effects on the variables are listed in (46):

$$
\begin{gathered}
\bar{\Delta} K=\bar{\Delta} Y=-1.8, \bar{\Delta} F_{m}=4.17, \bar{\Delta} N_{m}=3.21, \bar{\Delta} K_{m}=1.79, \bar{\Delta} F_{i}=-0.45, \\
\bar{\Delta} K_{i}=-0.42, \bar{\Delta} X_{i}=-0.14, \bar{\Delta} N_{i}=\bar{\Delta} N_{x}=\bar{\Delta} x=-4.5, \bar{\Delta} \pi_{0}=-0.44, \\
\bar{\Delta} \pi_{m}=0.93, \bar{\Delta} r=-0.03, \bar{\Delta} w=0.01, \bar{\Delta} p_{\epsilon}=0.01, \bar{\Delta} p_{m}=-2.2, \\
\bar{\Delta} \hat{y}=-1.8, \bar{\Delta} \bar{k}=-1.8, \bar{\Delta} c_{i}=-0.46, \bar{\Delta} c_{m}=4.18, \bar{\Delta} U=-0.02
\end{gathered}
$$

The monopoly produces more output and employs more labor force and capital stock. Its profit is increased in association with fall in its price. The national capital and national income are reduced. The final goods sector produces less and employs less capital, intermediates and labor force. The representative firm in the intermediate sector employs less labor force and produces less. Its profit falls in association of rise in its price. The wage rate is increased. The interest rate is decreased. The household's disposable income and wealth are reduced. The household consumes fewer final goods but more monopoly product. The utility level is reduced. As far as variable change directions are concerned, rises in the output elasticities of capital and labor have the opposite effects on the interest rate, wage rate, utility, and the price of intermediates, but the same effects on the other variables.

\subsection{A Rise in Degree of Specialization}

We now examine what happen to the economic structure as we change the degree of specialization as follows: $n=10 \Rightarrow 11$. The effects on the variables are listed in (47):

$$
\begin{gathered}
\bar{\Delta} K=\bar{\Delta} Y=10.9, \bar{\Delta} F_{m}=-2.88, \bar{\Delta} N_{m}=-5.8, \bar{\Delta} K_{m}=4.36, \bar{\Delta} F_{i}=11.8 \\
\bar{\Delta} K_{i}=11.7, \bar{\Delta} X_{i}=7.16, \bar{\Delta} N_{i}=\bar{\Delta} N_{x}=0.83, \bar{\Delta} x=-8.34, \bar{\Delta} \pi_{0}=1.66 \\
\bar{\Delta} \pi_{m}=4.03, \bar{\Delta} r=0.1, \bar{\Delta} w=10.9, \bar{\Delta} p_{\epsilon}=10.9, \bar{\Delta} p_{m}=7.3, \bar{\Delta} \hat{y}=10.9
\end{gathered}
$$




$$
\bar{\Delta} \bar{k}=10.9, \quad \bar{\Delta} c_{i}=11.9, \bar{\Delta} c_{m}=-2.88, \bar{\Delta} U=18.3
$$

The monopoly produces less output and employs less labor force but more capital stock. Its profit is increased in association with rise in its price. The national capital and national income are augmented. The final goods sector produces more and employs more capital, intermediate goods and labor force. The representative firm in the intermediate sector employs more labor force and produces less. Its profit rises in association of rise in its price. The wage rate is enhanced. The interest rate is increased. The household's disposable income and wealth are increased. The household consumes more final goods but less monopoly product. The utility level is enhanced.

\subsection{An Improvement in Human Capital}

We fistt study what happen to the economic system if the degree of specialization is increased as follows: $h=3 \Rightarrow 3.1$. The effects on the variables are listed in (48):

$$
\begin{gathered}
\bar{\Delta} K=\bar{\Delta} Y=3.3, \bar{\Delta} F_{m}=3.3, \bar{\Delta} N_{m}=3.3, \bar{\Delta} K_{m}=3.3, \bar{\Delta} F_{i}=3.3, \\
\bar{\Delta} K_{i}=3.3, \bar{\Delta} X_{i}=1, \bar{\Delta} N_{i}=\bar{\Delta} N_{x}=\bar{\Delta} x=3.3, \bar{\Delta} \pi_{0}=3.3, \\
\bar{\Delta} \pi_{m}=3.3, \bar{\Delta} r=-0.001, \bar{\Delta} w=\bar{\Delta} p_{\epsilon}=0.0003, \bar{\Delta} p_{m}=0.01, \bar{\Delta} \hat{y}=3.3, \\
\bar{\Delta} \bar{k}=3.3, \bar{\Delta} c_{i}=3.3, \bar{\Delta} c_{m}=3.3, \bar{\Delta} U=5.7 .
\end{gathered}
$$

All the variables are increased except the capital cost.

\section{Concluding Remarks}

This paper examined interdependence between economic growth and changes of market structures. It constructed a growth model of monopoly, perfect competition, and monopolistic competition with the growth mechanism of neoclassical growth theory. The model was established by integrating a few well-established economic theories. The model was framed with the Solow-Uzawa growth model with economic structure. The monopolistic competition is described as in the monopolistic competition Dixit-Stiglitz model. The monopoly is described in the same way as in standard monopoly theory. The behavior of the household was described with Zhang's utility function and concepts of current and disposable incomes. The paper made a unique contribution to the literature of economic structural change and growth by integrating these theories in a single formal framework. The model contains the endogenous determination of profits of monopolistic competition and monopoly. These profits were homogenously distributed among the population. As our model is constructed with some economic theories and each theory has a great number of research papers, we can extend and generalize our model by following some ideas in the extensive literature.

\section{References}

Azariadis, C. (1993). Intertemporal Macroeconomics. Oxford: Blackwell.

Barro, R. J., \& Sala-i-Martin, X. (1995). Economic Growth. New York: McGraw-Hill, Inc.

Behrens, K., \& Murata, Y. (2007). General Equilibrium Models of Monopolistic Competition: A New Approach. Journal of Economic Theory, 136, 776-87.

https://doi.org/10.1016/j.jet.2006.10.001 


\section{Al Macrothink}

Business and Economic Research ISSN 2162-4860 2021, Vol. 11, No. 2

Behrens, K., \& Murata, Y. (2017). City Size and the Henry George Theorem under Monopolistic Competition. Journal of Urban Economics, 65, 228-35. https://doi.org/10.1016/j.jue.2008.12.004

Benassy, J. P. (1996). Taste for Variety and Optimum Production Patterns in Monopolistic Competition. Economics Letters, 52, 41-7. https://doi.org/10.1016/0165-1765(96)00834-8

Ben-David, D., \& Loewy, M. B. (2003). Trade and Neoclassical Growth Model. Journal of Economic Integration, 18(1), 1-16. https://doi.org/10.11130/jei.2003.18.1.1

Bertoletti, P., \& Etro, F. (2015). Monopolistic Competition When Income Matters. The Economic Journal, 127, 1217-43. https://doi.org/10.1111/ecoj.12329

Brakman, S., \& Heijdra, B. J. (2004). The Monopolistic Competition Revolution in Retrospect. Cambridge: Cambridge University Press.

Burmeister, E., \& Dobell, A. R. (1970). Mathematical Theories of Economic Growth. London: Collier Macmillan Publishers.

Dixit, A., \& Stiglitz, J. E. (1977). Monopolistic Competition and Optimum Product Diversity. American Economic Review, 67, 297-308.

Ethier, W. J. (1982). National and International Returns to Scale in the Modern Theory of International Trade. American Economic Review, 72, 389-405.

Grossman, G. M., \& Helpman, E. (1990). Comparative Advantage and Long-Run Growth. The American Economic Review, 80(4), 796-815.

Jensen, B. S., \& Larsen, M. E. (2005). General Equilibrium Dynamics of Multi-Sector Growth Models. Journal of Economics, 10, 17-56. https://doi.org/10.1007/3-211-26650-X_2

Krugman, P. R. (1979). A Model of Innovation, Technology Transfer, and the World Distribution of Income. Journal of Political Economy, 87, 253-66.

https://doi.org/10.1086/260755

Lancaster, K. (1980). Intra-industry Trade under Perfect Monopolistic Competition. Journal of International Economics, 10, 151-75. https://doi.org/10.1016/0022-1996(80)90052-5

Mas-Colell, A., Whinston, M. D., \& Green, J. R. (1995). Microeconomic Theory. Oxford: Oxford University Press.

Nocco, A., Ottaviano, G. L. P., \& Salto, M. (2017). Monopolistic Competition and Optimum Product Selection: Why and How Heterogeneity Matters. Research in Economics, 71, 704-17. https://doi.org/10.1016/j.rie.2017.07.003

Nikaido, H. (1975). Monopolistic Competition and Effective Demand. New Jersey: Princeton University Press.

Parenti, M., Ushchev, P., \& Thisse, J. F. (2017). Toward a Theory of Monopolistic Competition. Journal of Economic Theory, 167, 86-115.

https://doi.org/10.1016/j.jet.2016.10.005 


\section{Macrothink}

Business and Economic Research ISSN 2162-4860 2021, Vol. 11, No. 2

Picard, P. M., \& Toulemonde, E. (2009). On Monopolistic Competition and Optimal Product Diversity: Workers' Rents Also Matter. Canadian Journal of Economics, 111(2), 1347-60. https://doi.org/10.1111/j.1540-5982.2009.01553.x

Romer, P. M. (1990). Endogenous Technological Change. Journal of Political Economy, 98(2), S71-S102. https://doi.org/10.1086/261725

Solow, R. (1956). A Contribution to the Theory of Economic Growth. Quarterly Journal of Economics, 70, 65-94. https://doi.org/10.2307/1884513

Uzawa, H. (1961). On a Two-Sector Model of Economic Growth. Review of Economic Studies, 29, 47-70. https://doi.org/10.2307/2296180

Wang, W. W. (2012). Monopolistic Competition and Product Diversity: Review and Extension. Journal of Economic Surveys, 26(5), 879-910.

https://doi.org/10.1111/j.1467-6419.2011.00682.x

Zhang, W. B. (1993). Woman's Labor Participation and Economic Growth - Creativity, Knowledge Utilization and Family Preference. Economics Letters, 42, 105-10.

https://doi.org/10.1016/0165-1765(93)90181-B

Zhang, W. B. (2005). Economic Growth Theory. Hampshire: Ashgate.

Zhang, W. B. (2018). An Integration of Solow's Growth and Dixit-Stiglitz's Monopolistic Competition Models. SPOUDAI Journal of Economics and Business, 64(4), 3-19.

Zhang, W. B. (2020). The General Economic Theory: An Integrative Approach. Switzerland: Springer International Publishing. https://doi.org/10.1007/978-3-030-56204-5

\section{Appendix}

\section{A1: Solving the Consumer Problem}

We optimize the utility function (19) subject to (18). We define the following Lagrangian function:

$$
L=\left(\xi_{m} c_{m}^{\xi_{0}}+\xi_{i} c_{i}^{\xi_{0}}\right)^{1 / \xi_{0}} s^{\lambda_{0}}+b\left(\hat{y}-p_{m} c_{m}-c_{i}-s\right)
$$

Maximizing L, we get

$$
\begin{gathered}
\frac{\partial L}{\partial c_{m}}=\frac{\xi_{m} c_{m}^{\xi_{0}-1}}{\xi_{m} c_{m}^{\xi_{0}}+\xi_{i} c_{i}^{\xi_{0}}}-\frac{p_{m} b}{U}=0 \\
\frac{\partial L}{\partial c_{i}}=\frac{\xi_{i} c_{i}^{\xi_{0}-1}}{\xi_{m} c_{m}^{\xi_{0}}+\xi_{i} c_{i}^{\xi_{0}}}-\frac{b}{U}=0 \\
\frac{\partial L}{\partial s}=\frac{\lambda_{0}}{s}-\frac{b}{U}=0
\end{gathered}
$$




$$
\frac{\partial L}{\partial b}=\hat{y}-p_{m} c_{m}-c_{i}-s=0
$$

From (A2) and (A3) we have:

$$
\frac{c_{m}}{c_{i}}=P \equiv \xi^{\frac{1}{\left(\xi_{0}-1\right)}} p_{m}^{\frac{1}{\left(\xi_{0}-1\right)}}
$$

where $\xi \equiv \xi_{i} / \xi_{m}$. Insert (A6) in (A3):

$$
\frac{\xi_{i}}{\left(\xi_{m} P^{\xi_{0}}+\xi_{i}\right)}-\frac{c_{i} b}{U}=0
$$

From (A4)-(A7) we solve:

$$
\frac{U}{b}=\left(\frac{P^{\xi_{0}}+\xi}{\xi p_{m} P+\lambda_{0} P^{\xi_{0}}+\xi+\lambda_{0} \xi}\right) \hat{y}
$$

From (A8) and (A4), we have:

$$
s=\left(\frac{P^{\xi_{0}}+\xi}{\xi p_{m} P+\lambda_{0} P^{\xi_{0}}+\xi+\lambda_{0} \xi}\right) \lambda_{0} \hat{y}
$$

By (A8), (A2) and (A3) we solve:

$$
\begin{aligned}
c_{i} & =\frac{\xi \hat{y}}{\xi p_{m} P+\lambda_{0} P^{\xi_{0}}+\xi+\lambda_{0} \xi} \\
c_{m} & =\frac{\xi P \hat{y}}{\xi p_{m} P+\lambda_{0} P^{\xi}+\xi+\lambda_{0} \xi}
\end{aligned}
$$

\section{A2: Checking the Lemma}

By (3) and (28) we obtain

$$
z \equiv \frac{r+\delta_{k}}{w}=\frac{\bar{\beta}_{i} N_{i}}{K_{i}}=\frac{\bar{\beta}_{m} N_{m}}{K_{m}}
$$

where $\bar{\beta}_{x} \equiv \alpha_{x} / \beta_{x}$. From (12) we have:

$$
p_{\varepsilon}=\frac{a_{N} w}{\theta}
$$

From (3), we have:

$$
w=\frac{\beta_{i} p_{\varepsilon} n x}{\gamma_{i} \theta N_{i}}
$$

where we apply (14). With (A2) and (A3), we get:

$$
N_{i}=a x
$$

where 


$$
a \equiv \frac{\beta_{i} n a_{N}}{\gamma_{i} \theta^{2}}
$$

By (2) we have:

$$
F_{i}=A_{i} N_{i}^{\beta_{i}+\alpha_{i}+\gamma_{i}}\left(\frac{K_{i}}{N_{i}}\right)^{\alpha_{i}}\left(\frac{X_{i}}{N_{i}}\right)^{\gamma_{i}}
$$

Insert (A1) and (A4) in (A5):

$$
F_{i}(x, z)=A_{i}(a x)^{\beta_{i}+\alpha_{i}+\gamma_{i}}\left(\frac{\bar{\beta}_{i}}{z}\right)^{\alpha_{i}}\left(\frac{n x^{\theta-1}}{a}\right)^{\gamma_{i}}
$$

From (3) and (A4), we have:

$$
w(x, z)=\frac{\beta_{i} F_{i}(x, z)}{a x}
$$

From (A4) and (30) we get:

$$
N_{m}(x)=h \bar{N}-\left(a_{N} n+a\right) x
$$

From (A1) and (A4) we have:

$$
K_{i}(x, z)=\frac{\bar{\beta}_{i} a x}{z}, K_{m}(x, z)=\frac{\bar{\beta}_{m} N_{m}}{z}
$$

Insert (A8) and (A9) in (23):

$$
F_{m}(x, z)=A_{m} N_{m}\left(\frac{\bar{\beta}_{m}}{z}\right)^{\alpha_{m}}
$$

Insert (A9) in (31):

$$
\bar{k}(x, z)=\frac{\bar{\beta}_{i} a x+\bar{\beta}_{m} N_{m}}{z \bar{N}}
$$

Fom (3) we have:

$$
r(x, z)=w z-\delta_{k}
$$

By (28), we have:

$$
H(x, z) \equiv\left(F_{m} \frac{\partial G}{\partial F_{m}}+G\right) \frac{\beta_{m} F_{m}}{N_{m}}-\left(\frac{1}{\bar{N}} \frac{\partial G}{\partial \tilde{y}}+1\right) w=0
$$

Assume that $H(x, z)=0$ has a unique solution, given by $z=\varphi(x)$. Insert this solution in (A11):

$$
\bar{k}=\bar{\varphi}(x) \equiv \frac{\bar{\beta}_{i} a x+\bar{\beta}_{m} N_{m}}{\varphi \bar{N}}
$$

We can straightforwardly confirm that we represent all the variables as functions of $x$ by the following procedure: $\bar{k}$ with (A14) $\rightarrow z$ by (A11) $\rightarrow K=\bar{k} \bar{N} \rightarrow F_{i}$ by (A6) $\rightarrow w$ by 
$(\mathrm{A} 7) \rightarrow r$ by $(\mathrm{A} 12) \rightarrow \pi$ by $(13) \rightarrow \bar{\pi}$ by (15) $\rightarrow X_{i}$ by (14) $\rightarrow p_{\varepsilon}$ by (A2) $\rightarrow N_{i}$ by $(\mathrm{A} 4) \rightarrow N_{m}$ by (A8) $\rightarrow K_{i}$ and $K_{m}$ by (A9) $\rightarrow F_{m}$ by (A10) $\rightarrow \varphi$ by (8) $\rightarrow p_{m}$ by (26) $\rightarrow \pi_{m}$ by (27) $\rightarrow \hat{y}$ by $(17) \rightarrow c_{i}, c_{m}$ and $s$ by (20). From this procedure and (21) we have:

$$
\dot{\bar{k}}=f(x) \equiv s-\bar{k}
$$

Derive (A14) in time:

$$
\dot{\bar{k}}=\frac{d \bar{\varphi}}{d x} \dot{x}
$$

From (A15) and (A16), we have:

$$
\dot{x}=\left(\frac{d \bar{\varphi}}{d x}\right)^{-1} f
$$

In summary, we proved the Lemma.

\section{Copyright Disclaimer}

Copyright for this article is retained by the author(s), with first publication rights granted to the journal.

This is an open-access article distributed under the terms and conditions of the Creative Commons Attribution license (http://creativecommons.org/licenses/by/4.0/). 